\title{
Anthropometric Evaluation of Lip Symmetry following Cronin Method Labioplasty for Unilateral Complete Cleft Lip and Palate Cases
}

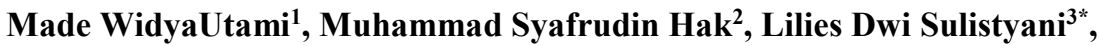 \\ Pradono Suhardi ${ }^{3}$ \\ ${ }^{1}$ Oral and Maxillofacial Surgery Residency Program, Faculty of Dentistry, Universitas Indonesia, \\ Indonesia \\ ${ }^{2}$ Department of Oral and Maxillofacial Surgery, Faculty of Dentistry, Universitas Indonesia, \\ Indonesia \\ ${ }^{3}$ Department of Oral and Maxillofacial Surgery, Faculty of Dentistry, Universitas Indonesia, \\ Indonesia \\ *Email: liliesdwi_s@yahoo.co.id
}

\begin{abstract}
Surgical treatment for patients with cleft lip aims at restoring facial balance and harmony. Cronin method labioplasty in patients with unilateral cleft lip and palate (UCLP) produces symmetrical lips with minimal scarring. This study evaluates lip symmetry following Cronin method labioplasty in patients with UCLP based on the protocol of the Cleft Center Harapan Kita General Hospital. Thirty-six patients with UCLP were photographed on the anterior side using a standardized method at 2 weeks, 1 month, 3 months, 6 months, and 1 year following Cronin method labioplasty. Cleft side lips were measured and compared with those on the opposite side. No significant differences were observed in the length of alar curvature points (ac) to the ipsilateral commissure or the distance from the Cupid's bow peak to the ipsilateral commissure on the cleft and noncleft sides. Significant differences were observed in the length from the subalar (sbal) to the Cupid's bow peak $(\mathrm{P}=0.007)$ between the cleft and noncleft sides at 2 weeks, 1 month, 3 months, and 6 months following labioplasty. The ratio of anthropometric measurements suggests that a symmetrical lip on the cleft and noncleft sides can be achieved at 1 year following Cronin method labioplasty.
\end{abstract}

Keywords: cleft lip, cleft palate, Cronin method labioplasty, lip symmetry, anthropometry

\section{Introduction}

A cleft lip is an abnormally shaped lip that is not fully formed because of failure in integration processes during embryo development. Surgical treatment for patients with cleft lip mainly aims at restoring facial balance and harmony [1]. Unilateral cleft lip repairing surgeries particularly aim at achieving symmetry and balance of the nose and lips, sufficient vermillion lip thickness, adequate upper lip length and projection in relation to the lower lip, scarring minimization, Cupid's bow improvement, philtrum line reshaping, tuberculum vermillion repair, and philtrum dimple restoration in the prolabium [2]. 
Almost all labioplasty cleft lip treatments leave scars that affect the vertical height and width of the upper lip [3]. Postoperative vertical scar tissue ("whistlelike" deformity) often shrinks, thereby making the height of the upper lip on the cleft side shorter than that on the noncleft side [4]. The Cleft Center at the Harapan Kita General Hospital performs labioplasty using the Cronin method. The advantages of this method are that it maintains the Cupid's bow, minimizes tissue removal, creates a symmetrical nostril floor, results in smooth scar tissue, and achieves symmetrical form and function of the lips. Few disadvantages of this method include bulky or dropping red lips on the cleft side [5]. All labioplasty operations were performed by the same oral and maxillofacial surgeon on patients aged $<1$ year, and protocol management of the cleft lip and palate was consistently implemented. As a result, surgical success evaluation is expected to provide an objective assessment with only a small bias. So far, no data are available regarding lip symmetry evaluation following Cronin method labioplasty in patients with UCLP based on the protocol by the Cleft Center at the Harapan Kita General Hospital.

\section{Methods}

Thirty-six patients with nonsyndromic UCLP that underwent Cronin method labioplasty at the Cleft Center, Harapan Kita General Hospital were photographed on the anterior side using a standardized method at 2 weeks, 1 month, 3 months, 6 months, and 1 year following surgery. All operations were performed by the same oral and maxillofacial surgeon. The cleft side lips were measured and compared with those on the opposite side. All data were processed using the SPSS 22.0 statistical software (Chicago, IL, USA) and analyzed using the unpaired t-test and one-way ANOVA. Anthropometric measurement is a method that uses anatomical landmarks for certain specific soft tissues [6].

\section{Results}

The present study was conducted at the Cleft Center, Harapan Kita General Hospital from March 2016 to May 2016. Table 1 presents results of the univariate analysis of the variables used in this study. Wilcoxon's test was used to identify differences in measurements taken by the first and second observers. As presented in Table 2, there was no significant difference $(\mathrm{P}>0.05)$ between the first and second observers in the measurement of the distance from the ipsilateral commissure to the ac point, distance from sbal to the peak of Cupid's bow, and distance from the peak of $\mathrm{Cu}$ pid's bow to the ipsilateral commissure. Pearson's correlation coefficient showed that intraobserver reliability was positively and strongly correlated

$$
(\mathrm{R} 2=0.924-0.972) \text {. }
$$

Tables 3, 4, and 5 present the results of the bivariate analysis. Table 3 indicates that there was no significant difference $(\mathrm{P}>0.05)$ in the distance from the ac point to the ipsilateral commissure between the noncleft side (line 1 ) and cleft side (line 2) at 2 weeks, 1 month, 3 months, 6 months, and 1 year, following labioplasty. Table 4 presents a significant difference $(\mathrm{P}<0.05)$ in the distance from the sbal point to the peak of Cupid's bow between the noncleft side (line 3 ) and cleft side (line 4) at 
2 weeks and 1 month following labioplasty, but no significant difference $(\mathrm{P}>0.05)$ at 3 months, 6 months, and 1 year, following labioplasty. Table 5 presents no significant difference $(\mathrm{P}>0.05)$ in the distance from the peak of Cupid's bow to the ipsilateral commissure between the noncleft side (line 5) and cleft side (line 6) at 2 weeks, 1 month, 3 months, 6 months, and 1 year, following labioplasty.

Anthropometric measurement is a method that uses anatomical landmarks for certain specific soft tissues. The landmarks and distances used in this study are presented in Figure 1: lines 1 (noncleft side) and 2 (cleft side) are the distance from the alar curvature (ac) point to the ipsilateral commissure, lines 3 (noncleft side) and 4 (cleft side) are the distance from the subalar (sbal) to the peak of Cupid's bow, and lines 5 (noncleft side) and 6 (cleft side) are the distance from the peak of Cupid's bow to the ipsilateral commissure.

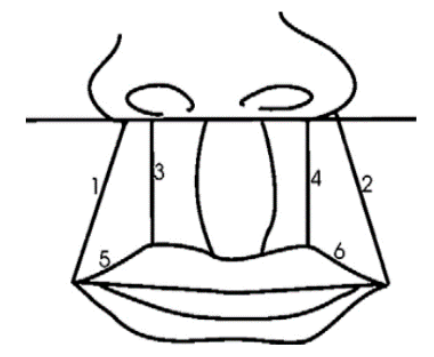

Fig 1. Landmarks and distances used in the present study. Length (lines 1 and 2: distance from the ac point to the ipsilateral commissure; lines 3 and 4: distance from sbal to the peak of Cupid's bow) and width of the upper lip (lines 5 and 6: distance from the peak of Cupid's bow to the ipsilateral commissure) [7].

The ratio of lip symmetry assessment in this study was between 0.95 and 1.05. Statistical analyses showed significant differences $(P<0.05)$ in the one-way ANOVA between the ratio A3/A4 at 2 weeks, 1 month, 3 months, and 6 months, following labioplasty.

\section{Discussion}

Most surgeons delay labioplasty until a patient reaches an approximately 3 -month age, which is the time when the lips become thick enough to be surgically repaired [8]. Recently, labioplasty has been performed at a 6-month age. At age 1 year, the lip height reaches $80 \%$ of the adult lip height in both males and females. The growth in lip height between 1 and 2-year age is important in determining adult lip size. Hence, labioplasty must be performed when the patient is aged $<1$ year [7]. The second peak in upper lip development occurs at age $>5$ years, hence, secondary repair should be performed between the ages of 3 and 5 years [4].

The distance from the ac point to the ipsilateral commissure at the noncleft side (1) is longer than that at the cleft side (2) at 2 weeks, 1 month, and 3 months postlabioplasty. This can happen because the upper lip growth primarily occurs laterally. The growth rate of the upper lip height is lower than that of the upper lip width. [9] All labioplasty methods leave a vertical scar that has a greater effect on the upper 
lip height than the upper lip width. [10] During the first weeks of healing, when the scar is red and swollen, the corrected cleft side is usually shorter than the noncleft side; however, it adjusts itself with greater lateral lip growth as the patient reaches adulthood. The distance from the sbal point to the peak of Cupid's bow between the noncleft side (A3) and cleft side (A4) shows significant differences at 2 weeks and 1 month following labioplasty, and the A3/A4 ratios at 2 weeks, 1 month, 3 months, and 6 months following labioplasty show lip asymmetry. This happens because A4 is close to the vertical scar tissue that often shrinks following labioplasty, thus reducing the upper lip height on the cleft side.

\section{Conclusion}

Anthropometric measurements using standardized photographs indicate that a symmetrical lip on the cleft and noncleft sides can be achieved at 1 year following Cronin method labioplasty.

\section{Acknowledgements}

This study was supported by the PITTA Grant 2016 (No: 1950/UN2.R12/HLP.05.00/2016) from the Directorate for Research and Community Engagement, Universitas Indonesia.

\section{References}

1. Chou PY, Luo CC, Chen PK, Chen YR, Noordhoff MS, Lo LJ. Preoperative lip measurement in patients with complete unilateral cleft lip/palate and its comparison with norms. J Plast, Reconstruc Aesthetic Surg. 2013;66(4):513-7.

2. Shprintzen RJ, Bardach J. Cleft palate speech management: a multidisciplinary approach. Mosby Incorporated; 1995.

3. Demke JC, Tatum SA. Analysis and evolution of rotation principles in unilateral cleft lip repair. J Plast, Reconstruc Aesthetic Surg. 2011;64(3):313-8.

4. Zhu LY, Meng T, Shi B, Deng DZ. Anthropometric study of the upper lip of 1500 healthy children in Chengdu, Western China. Br J Oral Maxillofac Surg. 2008;46(7):554-60.

5. Cronin TD. A modification of the Tennison-type lip repair. The Cleft Palate J. 1966;3:376-82.

6. Farkas LG, Katic MJ, Hreczko TA, Deutsch C, Munro IR. Anthropometric proportions in the upper lip-lower lip-chin area of the lower face in young white adults. Am J Orthodont. 1984;86(1):52-60.

7. Xing H, Bing S, Kamdar M, Yang L, Qian Z, Sheng L, Yan W. Changes in lip 1 year after modified Millard repair. Int J Oral Maxillofac Surg. 2008;37(2):117-22.

8. Bilwatsch S, Kramer M, Haeusler G, Schuster M, Wurm J, Vairaktaris E, Neukam FW, Nkenke E. Nasolabial symmetry following Tennison-Randall lip repair: a three-dimensional approach in 10-year-old patients with unilateral clefts of lip, alveolus and palate. $\mathrm{J}$ Craniomaxillofac Surg. 2006;34(5):253-62.

9. Iliopoulos C, Mitsimponas K, Lazaridou D, Neukam FW, Stelzle F. A retrospective evaluation of the aesthetics of the nasolabial complex after unilateral cleft lip repair using the Tennison-Randall technique: A study of 44 cases treated in a single cleft center. J Cranio Maxillofac Surg. 2014;42(8):1679-83.

10. Kim SW, Park SO, Choi TH. Change in upper lip height and nostril sill after alveolar bone grafting in unilateral cleft lip alveolus patients. J Plast, Reconstruc Aesthetic Surg. 2012;65(5):558-63. 